\title{
Approaches to the structuring of the information model of the life cycle stages of a construction object
}

\author{
Elena Gusakova*, Alexey Ovchinnikov and Andrey Volkov \\ Moscow State University of Civil Engineering, Yaroslavskoe shosse, 26, Moscow, 129337, Russia
}

\begin{abstract}
In the context of the general trend to accelerate change, the actual goal of scientific research in the field of construction is to analyze and design the stages of the life cycle of a construction object. The object of the study becomes the information model of the life cycle of the building. It is studied and modeled based on the concept of real estate development and using the methods of project analysis of the construction project. The widest possibilities for obtaining and analyzing data on the state of a construction object, as well as the possibilities of systematizing information flows and information modeling of different periods of its life cycle, are realized in the approach of BIM modeling of buildings and structures. With the help of BIM-modeling tools, mandatory stages and possible phases of the life cycle of a building object can be represented as hierarchically and sequentially related information flows, in which the attributes of each stage of the life cycle are formed under the influence of the preceding stages and of special factors for the considered stage. As a result, the project documentation should reflect the decisions aimed at providing the necessary conditions and opportunities for subsequent periods of the life cycle of the construction object, as well as the most adapted for the predicted changes and transformations for all future stages and phases. The analysis of characteristics and the developed structure of simple and complex construction works allows determining for each stage and phase of the life cycle of a construction object: interconnection of information flows, composition and content of the information model of the building required for the work of specialists.
\end{abstract}

\section{Introduction}

Modern construction facilities, buildings and structures, constitute a strategic resource and material basis for the economic and functional development of built-up areas from megalopolises to small towns. A building or structure (construction object) is the central element, the final result and the goal of the construction production cycle, its characteristics are determined by the priorities of the many participants in the life cycle of the construction object, a set of structural elements and connections: production and non-production processes, enterprises, external factors. Under the general trend of accelerating change, the

\footnotetext{
* Corresponding author: GusakovaEA@mgsu.ru
} 
urgent task of building science and engineering is to ensure that design decisions made today become the basis of its additional operational efficiency during the life cycle of a building, rather than a source of additional problems and costs [1, 2, 3, 4].

\section{Methods}

Research in this direction is carried out within the framework of the concept of real estate development and the methods of project analysis of the full life cycle of a construction object, based on modern information technologies. To date, the widest possibilities for collecting, processing, systematizing information flows and data on the state of a construction object, as well as information modeling from different periods of its life cycle are implemented in the BIM modeling (Building Information Modeling) approach for buildings and structures $[8,9,10]$.

In construction, modeling provides an opportunity to study a real-life or projected capital construction object (as a central structural element of the corresponding system of construction production) for some key features. For the practical application of the method, we consider the functional requirements for the formation of a model (object of research), which in its indicators completely or with a sufficient degree of assumptions corresponds to the characteristics of a real object for each of the mandatory or possible periods of its life cycle.

The scientific and methodological basis necessary for the formation of the required quality of models includes the main principles of the similarity theory - the similarity of the real object of research and the object of the model. It consists in such a mutual and unambiguous correspondence, in which the format of the transition function of the parameters characterizing the object - model to the corresponding parameters of the real object is known, and the mathematical descriptions of the transition can be transformed into the corresponding identities $[1,5,11]$.

Depending on the quantity and quality of the formalization of relationships (random events and facts), an appropriate method of describing the causes and effects in the model is adopted. The most complete correspondence of the object - model to the real object of research is achieved by the simultaneous similarity in space and time of its functioning.

\section{Results}

The development of the construction industry as a whole, a specific construction enterprise, and participants in the construction industry of each individual construction project are in a state of unstable dynamic interaction with changes in economic, functional and technological processes and conditions $[11,12.13]$. They form the priority requirements for the structure, functional purpose and necessary transformations of both the urban environment and the construction objects that make it up.

The life cycle of a construction object of any functional purpose has the form of an oriented structure with the main stages or periods (Fig. 1.). 


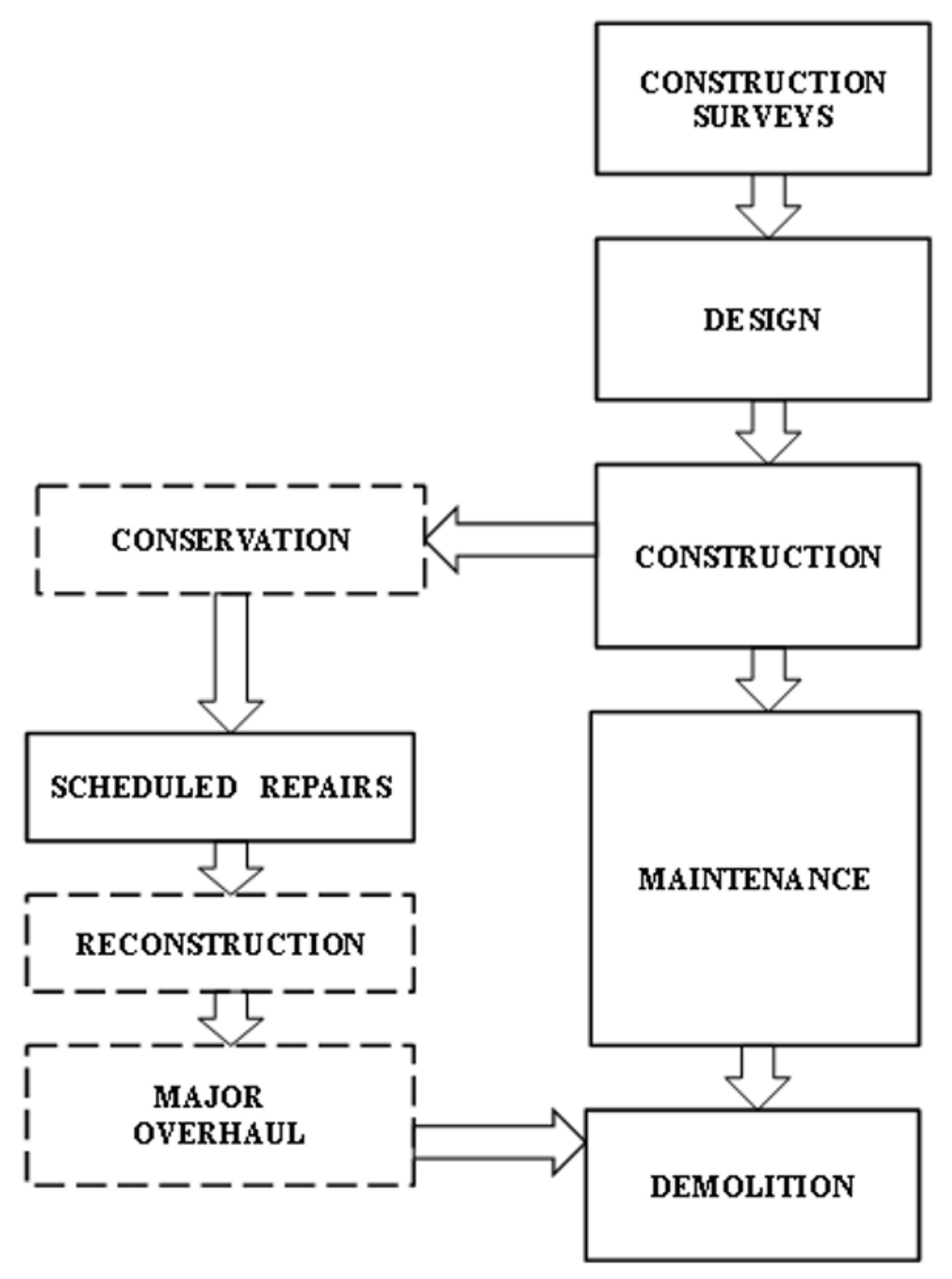

Fig. 1. Oriented structure life cycle of a construction object with mandatory stages and possible phases.

For each of the mandatory and possible stages and phases of the life cycle, the effect of groups and individual factors of influence of a different nature is characteristic. Features of the manifestation of many factors of influence determine the qualitative and quantitative parameters and signs of the state and conditions of development of a construction object. The duration of periods of the life cycle of a construction object is not the result of any one, but is formed as a result of the interaction of various factors of influence or groups of factors of influence $[14,15,16]$. The most important factors of influence may include: technical and economic constraints that determine the size and scale of construction projects; opportunities for long-term growth and development of a functional-territorial organization; subjective preferences of participants in the process of building products formation (state representatives or individuals); property conditions and tax burden. 
One of the obvious features of the life cycle of a construction object is a certain consistent subordination and dependence of its individual stages. This circumstance allows us to make an assumption that the effectiveness of each subsequent period of the life cycle is determined by the composition and quality of the decisions established and implemented in the previous period or periods [17].

Thus, for example, indicators of the efficiency of operation of a residential building (for example, before the first scheduled repair) are determined by the quality of decision making at the design stage (quality of the structural system) and the quality of the construction processes (the building system) during the construction of the building. At the same time, the quality of the construction project and the effectiveness of the adopted and implemented project decisions can be adequately assessed only after all stages of its life cycle have been completed $[18,19]$.

\section{Discussion}

It is logical to assume that the priorities of systematization of information flows and the choice of design solutions for a construction object are determined by the features of the stages of its life cycle and the features of the inverse relationships between stages and phases. Depending on the features and complexity of the construction object and the available methods for obtaining, accumulating and processing data, structured information flows and an information model of the object are formed, characterizing the planned indicators and actual parameters of the state of the construction object for the stages of the life cycle $[18,20]$.

The first mandatory stage of the life cycle of a construction object is construction surveys. It includes a set of economic and engineering studies that establish the economic feasibility of locating and operating a construction object in the considered building area [21]. In the composition of economic research systematized the results of studying options:

- provision of construction production with local building materials, water, electricity;

- $\quad$ use of production capacity of local construction companies and contractors;

- use of existing condition and / or development of local transport infrastructure.

Engineering surveys include a complex of studies of the area and construction site to take into account the specific conditions of the surrounding artificial and natural environment and to systematize the initial data for the design and construction periods of the object.

Obligatory stage of the life cycle of a construction object is design, which includes the processes of modeling and integration of the subsystems of the future building by various groups of specialists. The design of the functional characteristics of a construction object is carried out on the basis of information flows (results and data) obtained during economic and engineering surveys.

Indicators of functional efficiency of construction objects are characterized by the quality of design solutions and structural systems, the level of reliability of structural elements and assemblies of their connections, technical and technological perfection of the methods of practical implementation of construction systems, their adaptability to the implementation of subsequent stages and phases. The result of the work is the project (technical documentation) of the construction object, which displays the constructive and organizational and technological solutions of the construction industry [22].

At the design stage of a construction object, design solutions, parts and sections of project documentation are reviewed, analyzed and agreed with interested organizations, representatives of local administration and state control bodies. On the final segment of the design of a construction object, in accordance with the existing regulatory documents, the 
expert examination of design solutions (of technical documentation).In the course of the project, the project is checked for compliance with the design assignment, the quality and accuracy of the decisions made, the level of the modern construction base, the progressiveness of the adopted design and architectural solutions for the facility, the methods of organizing and mechanizing the construction processes..

As a result, the project (technical) documentation should reflect solutions focused on manufacturability and providing mandatory conditions and opportunities for subsequent periods of the life cycle of the construction object, including:

- The possibility of ensuring an effective and safe organizational and technological sequence of construction of the facility;

- The possibility of ensuring the effective and safe operation of the designed building or structure and the requirements, including the maintenance of the structural elements of the building, the networks of its engineering and technical support systems;

- Ensuring the convenience of carrying out inspections and surveys of the technical state of the structural system, carrying out planned repairs during the operation of a building or structure;

- Ensuring the standard values of installation loads (for the construction period) and operational loads (for the operation period) for the construction and structural systems or individual elements of the designed construction object.

The construction stage in the life cycle of a building is a stage of practical realization of town planning, architectural, constructive and organizational and technological solutions. The construction phase is key to ensuring the characteristics and performance indicators established during construction survey and design periods. These characteristics and indicators determine the level of reliability and safety of the subsequent operation of a building or structure [23].

Information flows of this stage are formed on the basis of the organizational and technological sequence of its construction, which involves the implementation of simple and complex construction processes. Their structure, volume and composition is determined by the adopted structural system of the building, the parameters of the structural elements, as well as the uniqueness and technical complexity of the construction of the construction object.

Taking into account the possible impact of influencing factors in the production of construction processes is carried out by increasing (or introducing additional) technological interruptions into the composition and sequence of work (based on the provisions of standard process charts) - for typical construction systems. For unique building systems, the development and implementation of a technically complex (unique) sequence of construction processes and / or the use of a special protective set of measures are allowed.

The stage of maintenance of the erected construction object (new construction, reconstruction, expansion) constitutes the main and target stage of its life cycle [24]. Maintenance of the constructed construction object is carried out after obtaining permission to enter the facility into operation. To ensure the proper technical condition of the construction object, a system of operational control and repairs and the corresponding information model are being developed. Their task is to assess the technical condition and to carry out and maintain aesthetic, structural characteristics, as well as reliability and safety indicators at the established level, during the established service life of the building.

Evaluation of the technical condition is carried out within the framework of the information model by periodically checking the compliance of the characteristics of the structural systems and supporting structural elements. The purpose of the examination is to confirm the possibility of further operation of the construction object and compliance with the requirements of the provisions of the regulatory and design documentation in one or several possible ways: 
- Maintenance control - conformity assessment of the technical condition is carried out by the organization that operates the construction object;

- State control - assessment of compliance of a technical (or other type) condition is carried out by authorized federal executive bodies, executive bodies of constituent entities of the Russian Federation in cases and in the manner established by federal laws;

- Voluntary control - the conformity assessment of a technical (or other type) condition is carried out in the form of non-state expertise or other forms.

Planned maintenance and preventive measures ensure the preservation of the operational quality of structural systems and / or individual structural elements (especially bearing elements) and compensate for the negative effects of influence factors allowed in previous periods of the life cycle of a construction object (construction surveys, design, construction).

The final stage of the life cycle of a construction object is the mandatory stage demolition caused by its complete deterioration, the need for reconstruction, expansion or new construction. Transition to this period is possible when negative factors of influence manifest themselves in a critical format (for indicators of functional efficiency and level of operational safety) of the number of defects and damage to the structural system or individual structural bearing elements of a construction object $[25,26]$.

At any arbitrary moment of time, the technical condition of the structural system and/or individual structural elements of the operated building object is characterized as a functional or non-functional state. Accordingly, defects and damages are the main reasons for the transition of the considered structure to an inoperable state (the onset of an unacceptable state of physical wear). If it is impossible to bring a defective structural system or a damaged structural element to a working condition, it is necessary to conduct a special set of measures aimed at the completion of operation or demolition of a construction object.

The organizational and technological sequence of the demolition of a construction object is carried out in accordance with the specific features of the technical condition of the structural system, location in the structure of the surrounding urban development, and the requirements of regulatory documents. The need for such stages of a building life cycle, such as conservation, reconstruction, overhaul, is caused by a number of reasons:

- lack of capacity to ensure its operational suitability at an established or project level;

- the presence of a threat to environmental safety on the part of the construction object under consideration (including in the absence of critical signs of physical and moral deterioration);

- the need for significant measures aimed at a fundamental change in performance indicators or functional suitability.

Possible periods of the life cycle are considered only from the moment of completion of the facility construction stage. For example, the period of conservation is a kind of alternative to the period of operation at critically low indicators of the quality of operation of the corresponding construction object.

The transition, or rather the transfer of a construction object to each of the possible periods (states), is governed by regulatory documents or as a result of voluntary assessment of technical condition or moral wear and tear.

\section{Conclusion}

Thus, the required stages and possible phases of a construction object life cycle are hierarchically and sequentially related, with the signs of each stage of the life cycle being 
formed under the influence of the preceding stages and factors of influence of intangible and material origin specific to a particular stage.

The analysis of the characteristics and the developed structure of simple and complex construction works (processes), as well as the conditions necessary for their practical implementation, allows determining for each stage and stage of the life cycle of a construction object such functional requirements for the information model as:

- interconnection of information flows,

- the composition and content of the information model, which can provide the necessary information for professionals working and developing the construction object.

This work was financially supported by Ministry of Science and Higher Education of the Russian Federation (\#NSh-3492.2018.8).

\section{References}

1. S.Baronin, A. Porshakova Scientific aspects of determining and forecasting the economic reliability of development of complex residential development, Journal of Izvestia of the Penza State Pedagogical University, 24, 200-203 (2011)

2. S. Glazyev, G. Fetisov About the strategy of sustainable development of the Russian economy, Economic and social changes: facts, trends, forecast, 1 (25), 18-29 (2013)

3. A. Ginzburg, Organizational and technological reliability of building systems, Vestnik MGSU, 4, 251-255 (2010)

4. E. Gusakova, A. Krygina On the application of the innovative approach to change management in the process of implementation of investment and construction projects, Real Estate: Economics, Management, 2, 84-87 (2012)

5. A. A. Volkov, V. O. Chulkov, D. Korotkov Life cycle of a building, Advanced Materials Research, 1065-1069, 2577-2580 (2014)

6. A. Volkov, A. Ovchinnikov. Information model of a capital construction object, Science perspectives, 10, 12-15 (2018)

7. Ginzburg, A., Baranova, N. Blokhina, A. Volkov, N. Garyaev, V. Ginzburg, V. Ignatov, E. Ignatova, B. Istomin, P. Kagan, E. Kitintseva, V. Kulikov, S. Sinenko Systems of design automation in construction. (Moscow: Moscow State University of Civil Engineering) p 664 (2014).

8. K. Karen, N. Douglas Building Information Modeling: BIM in Current and Future Practice (USA: Wiley) p 432 (2014)

9. V.V. Poluektov Information Modeling Technologies (BIM) for architectural and town planning design, Architectural Studies, 1 (5), 46-55 (2016)

10. E.V. Litvinenko, I.A. Ustudganina The use of building information modeling (BIMtechnologies) in Russia, Economics and Business: Theory and Practice, 9, 64-66 (2015)

11. I.A. Kuzovleva, D.S. Marchenko Managing risk and uncertainty in assessing the effectiveness of a development project, Magazine "FEN-science" Bryansk, BGITA, 8 (2012)

12. V. Baburin Innovative cycles in the Russian economy (Moscow: Krassand) p 134 (2010)

13. A. Ginzburg, A. Skiba Creating an urban area planning design based on the theory of fuzzy logic, Applied Mechanics and Materials, Trans Tech Publications, Switzerland, Vols. 584-586, 507-511 (2014) 
14. O.A. Pobegailov, D.V. Lotshnikov Organizational and technological modeling of the system "design-construction-operation" in modern conditions, Science studies, 5, 1-5 (2013)

15. T. Kuzmina, S. Sinenko, A. Slavin Combining the functions of the main participants of investment and construction activities at the present stage, Industrial and civil construction, 6, 71-75 (2016)

16. S.A. Sinenko, E.S. Shtranina On the issue of the possible classification of construction projects by the degree of complexity, Scientific review, 6, 185-188 (2016)

17. E. Gusakova, Y. Ushakova Organizational and technological genesis of large-scale development projects in the Moscow region, Real Estate: Economics, Management, \#1, 54-60 (2015)

18. V.E. Telishenko, E.A. Korol, P.B. Kagan, E.N. Kulikova Systems engineering management of targeted construction programs (M.: Publisher ACB), p. 224, (2010)

19. E. Kolesnikova, T. Kuzmina, S. Sinenko Solution of organizational and technological problems (Moscow: Publisher ASV) p 96 (2015)

20. A.V. Ginzburg, E. Nesterova The technology of continuous information support for the life cycle of a construction site Scientific and Technical Journal Vestnik MGSU, 5, 317-320 (2011)

21. S.B. Sborshikov, N.V. Lazareva, Y.V. Zharov The structure and composition of the systems-model of sustainable development of investment and construction activities, Vestnik MGSU, 2, 210-218 (2014)

22. F. Harris, R. McCaffer, F. Edum-Fotwe. Modern Construction Management, (Chichester: Wiley-Blackwel), p. 411 (2013)

23. M. A. Chegodaeva The functionality of the information model at the stages of design, construction and operation of the building, Young scientist, 25, 102-105 (2016)

24. A.V. Demenev, A.S. Artamonov Information modeling in the operation of buildings and structures, Science studies, Book 7 (3), 1-9 (2015)

25. V.A. Kashtanov, A.I. Medvedev Theory of reliability of complex systems, (M.: Publisher Fizmatlit), p. 378, (2010)

26. V.N. Tsygichko, A.Yu. Popovich Synthesis of hierarchical control systems: Theory and practice, ( M .: KRASAND), p. 256, (2012) 